\title{
A ausência de identificação feminina com a "mulher sexuada" aparece em relacionamentos de longa duração
}

Jaqueline Brendler*

\section{RESUMO}

No presente texto sugerimos que há inexistência da identificação com a "fêmea", com a "mulher erotizada", em mulheres que têm desejo sexual hipoativo. Propomos que, para essas mulheres, durante o período da paixão é difícil a percepção dessa falta de identificação que se torna cada vez mais aparente nos relacionamentos a longo prazo, quando o desejo sexual mais freqüentemente diminui.

\section{INTRODUÇÃO}

Homens e mulheres são educados ainda hoje de maneira muito diferente em a relação à sexualidade. Contudo todos sabemos que no período da paixão o desejo sexual é muito intenso para ambos os sexos.

* Ginecologista com qualificação para o exercício da terapia sexual. Vice-Presidente da Região Sul da Sociedade Brasileira de Estudos em Sexualidade Humana -SBRASH. Membro da Comissão Nacional especializada em Sexologia da FEBRASGO. Coordenadora do Núcleo de Sexologia da SOGIRGS.

e-mail: jaqbrendler@cpevo.net

Recebido em 29.07.01

Aprovado em 15.08.01 
nas meninas ela se forma através da identificação com a figura materna ou outras figuras femininas significativas, mas também através da interação complementar com a figura paterna, que lhe dá a sensação de ser mulher em contraposição ao ser homem. O comportamento do pai em valorizar ou não a mãe no papel de mulher facilita ou dificulta a identificação da filha com a figura materna.

O mais comum é que desde o tempo que são meninas, a mulher identifica-se muito mais com o papel de mãe, que é muito mais valorizado do que com o papel de "mulher sexuada", oposto ao que acontece com os homens. Os pais não costumam dizer aos seus filhos que sexo é maravilhoso, que traz satisfação, aumenta auto-estima e proporciona maior união entre o casal. As meninas crescem ouvindo que sexo é pecado, sujeira, sofrimento. Elas repetidamente ouvem que sexo leva à gravidez $\mathrm{e}$ às DSTs. Todos esses sentimentos e medos tornam-se associados a sexualidade. Os meninos se permitem sentir prazer sexual mesmo na ausência do lado "nobre" da sexualidade. Eles se permitem mais serem transgressores dos papéis sexuais tradicionais. Os pais temem que suas filhas tenham uma iniciação sexual precoce e agem de modo a tentar adiar a sua vida sexual.

Qual o significado de ser mulher para a maioria das mulheres? Ser mãe, ser uma boa profissional?

No decorrer da vida as mulheres assumem vários papéis: o de filha, o de profissional, o de mãe e o de avó. Algumas mulheres, principalmente em relacionamentos a longo prazo, exercem os outros papéis sem terem "a mulher sexuada" internalizada e nesse tipo de situação as diferenças em relação à libido vão aparecer. Outras mulheres que têm essa identificação primária não apresentam queixas tão freqüentes em relação ao apetite sexual.

Outros fatores que contribuem para que essa falta de identificação primária apareça nos relacionamento a longo prazo é que muitas mulheres, hoje, acima dos 35, 40 anos que tiveram um único parceiro sexual vinculam a sua sexualidade à presença física do seu parceiro fixo, 0 marido. Durante $o$ período da paixão, como o desejo sexual é muito aumentado, elas não percebem o quanto, somente na presença dele, conseguem se erotizar. Durante a paixão a falta de identificação com "a mulher sexuada" passa despercebida. Com o tempo o único parceiro torna-se o agente desencadeador, promotor e mantenedor da sexualidade dela. Nos relacionamentos a longo prazo, a situação clínica acima mencionada pode ser detectada, quando a queixa é desejo sexual hipoativo feminino.

\section{PROPOSTA}

Sugerimos que se pense sobre qual o significado atual de "ser mulher". Se o significado mais importante para a maioria das mulheres ainda se restringe a "ser mãe", a "ser uma competente profissional" e não a ser tam- 
bém 'uma mulher sexuada' talvez seja mais fácil entender por que em relações duradouras, as mulheres iniciam uma experiência sexual de um estado de neutralidade sexual.

Homens e mulheres são diferentes em muitos aspectos, isto inclui também o sexual. Será que os fatores biológicos como a conformidade cerebral e os níveis de testosterona são os mais significativos para explicar as diferentes percepções do sexo entre a mulher e o homem?

Por que muitas mulheres conscientemente admitem uma motivação não sexual por "ganhos" e em função deles, deliberadamente aceitam o estímulo sexual? Não poderá haver uma falta da identificação primária com "a mulher sexuada"? A falta dessa identificação pode ser atribuída à educação repressora que ensinou as meninas a perceberem sexo como algo repulsivo, negativo, feio e pecaminoso e a hipervalorizar o papel de mãe e atualmente o papel profissional. Penso que as meninas são "programadas" para não terem a identificação de 'mulher sexuada' internalizada e apenas cumprem o seu destino.

Talvez o nosso papel como profissionais de saúde seja pensar sobre essa possibilidade, pois, se ela for aceitável, teremos que tratar os adultos para que percebam a sexualidade como algo maravilhoso e essencial para a felicidade humana, para que eles possam passar essa imagem positiva para as suas filhas mulheres de maneira que possa existir nelas também a identificação com a mulher sexuada.

\section{REFERÊNCIAS BIBLIOGRÁFICAS}

1. BASSON, R. The female sexual response: a different model. Journal of Sex \& Marital Therapy, 26: 51-65, 2000.

2. BASSON, R. et all. Report of the international consencus development conference on female sexual dysfunction: definitions and classifications. The Journal of Urology, 163, 888-893, 2000.

3. BASSON, R. Human sex-response cycles. Journal of Sex \& Marital Therapy, 27: 33-43, 2001.

4. BASSON, R. Are the complexities of women's sexual function reflected in the new consensus definitions of dysfunction? Journal of Sex \& Marital Therapy, 27: 105-112, 2001.

5. KAPLAN, H. S. The Sexual Desire disorder - Dysfunctional Regulation of sexual motivation. Brunner/ Mazel, INC. 1995. 